\title{
Problemas de expressão: figuras de conteúdo e figuras de expressão
}

\author{
Diana Luz Pessoa de Barros
}

A mesa-redonda sobre problemas de expressão * e o trabalho que nela apresentamos são decorrências de dois fatos. Em primeiro lugar, a organização da expressão e suas relações com o conteúdo encontramse entre as preocupações atuais da semiótica greimasiana, voltada, nos momentos iniciais de seu desenvolvimento e por razões diversas, ao tratamento apenas do plano do conteúdo. Em segundo lugar, o reconhecimento de sistemas semióticos sincréticos, como o cinema ou a canção popular, e daqueles de elaboração secundária, como a linguagem poética ou a plástica, em que não se pode prescindir do exame das correlações estabelecidas entre expressão e conteúdo, apressou a retomada de tais estudos.

Confundem-se, como problemas de expressão, orientações diversas, questões muitas vezes sobejamente discutidas e nem por isso bem resolvidas. Selecionamos três delas, entre as mais gerais, para aqui discuti-las: separação de expressão de conteúdo, para a análise; elaborações secundárias da expressão; relações entre dois ou mais sistemas semióticos. São caminhos que já estão sendo ou, a nosso ver, merecem ser investigados pela semiótica. (1)

1 - Pretendemos salientar, inicialmente, a necessidade de analisar expressão e conteúdo como organizações hierárquicas independentes, mesmo quando, no caso da expressão, os objetivos da abordagem forem a construção da significação e a recuperação dos efeitos de sentido. Melhor dizendo, não se pode restringir o exame da expressão aos casos em que se procura explicar o componente fonético -

* Uma primeira versāo deste texto foi apresentada no I Colóquio Luso-Brasileiro de Semiótica, realizado em Niterói, em setembro de 1984. 
fonológico das gramáticas, solucionar dificuldades fonoaudiológicas ou catalogar cores. É preciso tratá-la, também do ponto de vista da semiótica.

Trabalhos práticos, especialmente com objetos visuais e textos poéticos verbais, têm levado os investigadores a reconhecer organizações secundárias da expressão e relações entre expressão e conteúdo que não se confundem com a determinação de formantes da expressão, quase invisíveis na função única de suportarem o significado. A teoria literária faz alusão à "literariedade" propriedade "singular" do fato literário (2), mas é, sem dúvida, a pintura, lançada na aventura da figuração e da abstração, que se coloca como lugar privilegiado para a abordagem da questão. Em Girassóis de VAN GOGH (3), por exemplo, não basta reconhecer as figuras do vaso e das flores que murcham e perdem as pétalas; é preciso construir ainda oposições de expressão cromáticas - claro vs escuro, saturado vs não-saturado, puro vs impuro, quente vs frio - , de forma - contornos rotundos vs angulares, regulares vs irregulares, derivados do círculo vs derivados do retângulo - e a combinação de tais elementos (4), da mesma forma que na aquarela Blumen-Mythos, de KLEE (5), importa identificar o pássaro, a flor ou o torso de mulher, mas também caracterizar distinções de cor, de forma e de localização no espaço. Cabe observar que as oposições determinadas são formais e que, por conseguinte, manifestaçōes cromáticas aparentemente idênticas podem ser consideradas, num texto, como ocorrências do traço claro e, em outro, do escuro.

2 - É nossa intenção mostrar, como segundo ponto da proposta inicial, a relevância da definição de relações entre expressão e conteúdo, principalmente para os sistemas semi-simbólicos. Os sistemas semi-simbólicos distinguem-se dos sistemas simbólicos (as linguagens formais, por exemplo) e das linguagens stricto sensu (as línguas naturais), na acepção de Hjelmslev: as relaçōes são estabelecidas entre categorias e não entre termos isolados da expressão e do conteúdo. Há, assim, conexão, em Blumen-Mythos, entre /curvo vs reto/ e /celeste vs terrestre/, entre /alto vs baixo/ e /celeste vs terrestre/, entre /elementos lineares vs elementos de superfície/ e /animado vs inanimado/; em Girassóis, entre /claro e puro vs escuro e impuro/ e /juventude vs velhice/; em Desenredo, conto de Guimarães Rosa (6), entre /friç̧ão vs não-fricção/ (7) e /evasão, criação vs conservação, limitação/; em Os reinos do amarelo, poema de João Cabral de Melo Neto (8), entre /aberto e claro de/a/ vs fechado e sombrio de / $/$ / e de /o/ e/natural de vegetal e mineral vs cultural de animal humano/ (9). 
Os sistemas semi-simbólicos, conforme observado, ocorrem como linguagens secundárias, plásticas no visual e poéticas no verbal, ou melhor, como novas e superpostas relações entre o plano da expressão e o do conteúdo. Muito provavelmente seja a denominação de poética a mais adequada a tais organizações segundas da expressão correlacionadas a categorias abstratas do conteúdo, quer se trate de pintura, poesia ou dança. Agregados a linguagens, no sentido estrito acima referido, os sistemas semi-simbólicos dominam-nas, muitas vezes, invertendo-se a hierarquia, como parece acontecer na pintura e na poesia "abstratas" (ou "concretas"?).

As reflexões acima retomam questões de iconicidade e de motivação, sejam elas as dos signos visuais, ditos icônicos, sejam as dos recursos onomatopaicos do verbal, mas o caminho proposto faz aparecerem especialmente procedimentos pelos quais um novo saber sobre o mundo se instaura. Resulte tal saber de formações ideológicas e de condições sócio-históricas específicas ou de marcas individuais de estilo, surgem, de qualquer forma, a originalidade e a criatividade, do grupo ou do indivíduo, que levam a ler o mundo de outras maneiras: 0 claro e o puro cromático da expressão suportam os traços de vida e de juventude (10) ou a continuidade e o ruído do / $\mathrm{v} /$ expressam a fuga para o imaginário e sua recriação como outra e "verdadeira" realidade (11).

Os sistemas semi-simbólicos instalam, dessa forma, o novo, o inesperado ou o imprevisível, enquanto as relações "propriamente lingüísticas" encontradas entre expressão e conteúdo no poema ou na instância figurativa da pintura se caracterizam pela imotivação do convencional e pela necessariedade ou consubstancialidade de $\mid$ Benveniste, garantias da comunicação.

Estamos já na terceira e última questão apresentada, a das relaçōes intersemióticas. As relações intersemióticas englobam, na nossa opinião, as relaçōes "referenciais" vigentes entre uma semiótica qualquer e a semiótica do mundo natural, o sincretismo dos quadrinhos, do cinema ou da canção popular, que não será desenvolvido neste trabalho, e, ainda, as elaborações secundárias da expressão a que acima nos referimos.

3 - As noções de figura e de figurativização, diluídas até agora no texto, serão recuperadas mais detalhadamente.

Entendemos, com Greimas (1 2 ) que as relações "referenciais" são intersemióticas, isto é, que categorias do plano da expressão do mundo natural se tornam categorias do conteúdo das línguas naturais 
(as categorias áspero vs liso e contínuo vs descontínuo servem de exemplo), constituindo as figuras do conteúdo, e que, inversamente, categorias do conteúdo das línguas naturais respondem pela organização abstrata do mundo natural (as categorias humano vs vegetal, natural vs cultural e velho vs jovem exemplificam o fato). Há assim duas dimensões no plano do conteúdo das línguas, uma figurativa, caracterizada por traços, mais "concretos" das diferentes ordens sensoriais de apreensão do mundo, e outra, mais abstrata, resultante da organização interna da própria língua, leitura humana do mundo.

Os textos conservam, muita vezes, as duas dimensões, sob a forma de elementos disseminados em percursos figurativos ou temáticos isotópicos, devendo-se entender a figurativização discursiva do conteúdo, que caracteriza as línguas naturais e também o reconhecimento, nos textos visuais, dos objetos do mundo, como uma cobertura semântica mais concreta da abstração temática. A figura da flor que fenece recobre, em Girassóis, o tema do envelhecimento, da passagem da vida à morte, enquanto navegação, com o mar, barcos, mastros $\mathrm{e}$ velas, constitui, em Desenredo, um dos investimentos figurativos da evasão.

Retomando as observações apresentadas sobre as novas correlações entre expressão e conteúdo nos sistemas semi-simbólicos, podemos concluir que certas categorias ocorrem tanto como figuras da expressão, plásticas ou poéticas, quanto como figuras do conteúdo, e reconhecer, assim, dois procedimentos semióticos diferentes de "concretização" de conteúdos temáticos abstratos. A categoria do valor de claro vs escuro pode servir de exemplo: em Girassóis, participa da figura de expressão visual correlata à categoria do conteúdo de juventude vs velhice e, em Os reinos do amarelo, pertence à figura cromática de conteúdo que cobre o tema da natureza e da cultura.

Os dois recursos de figurativização são empregados separadamente ou em combinações diversas, no fazer textual. Uma das possibilidades é um mesmo percurso temático receber, no texto, investimento de figuras de conteúdo e de figuras de expressão do sistema semisimbólico secundário. Em Desenredo, por exemplo, o tema da evasão está tratado tanto pelas figuras de conteúdo de navegação, quanto pela figura de expressão de fricção contínua. Em Os Reinos do Amarelo os conteúdos abstratos de natural vs cultural são tornados mais concretos pelas categorias figurativas de conteúdo de claro vs escuro, de brilhante vs opaco, de puro vs impuro, de estridente vs silencioso, de quente 
vs frio, entre outras, e pelas categorias de expressão de aberto vs fechado e de som claro vs som sombrio. (13)

A figurativização da expressão e a do conteúdo, embora realizem o fim comum de transmitirem de forma mais concreta conteúdos abstratos, têm, porém, funções diferentes, se pensadas no quadro das relações enunciativas, e geram efeitos de sentido distintos. As conexões entre expressão e conteúdo nos sistemas semióticos semisimbólicos, como vimos, colocam em questão a leitura convencional das coisas e propõem um novo saber sobre o mundo. Criam, portanto, para o enunciatário, efeitos de verdade. Tornar os textos mais ou menos figurativos, recorrendo a figuras do conteúdo, é, por sua vez, um dos recursos pelos quais o enunciador persuade o enunciatário do caráter real ou irreal do mundo que procura fazer passar. A produção da ilusão referencial caracteriza assim as semióticas figurativas, incluídas aí também as que visam a causar o ef eito contrário de abstração ou de irrealidade.

Tais considerações levam-nos a repensar o problema da iconicidade também nos textos visuais, onde a questão está mais profundamente enraizada. $O$ primeiro passo parece ser reler as relações de representação e de reconhecimento, que ligam enunciador e enunciatário, como um contrato fiduciário, como um jogo de manipulação, persuasão e interpretação, respectivamente. Não se trata mais de imitar o mundo, mas de fazer crer que isso foi feito - efeito de sentido de real ou de referente (14) - , ao mesmo tempo que, através sobretudo do plástico e do poético, procura-se recriá-lo - efeito de sentido de verdade.

Esperamos ter conseguido levantar alguns dos problemas que envolvem o tratamento semiótico do plano da expressão. Foi nosso objetivo enfatizar a necessidade, também do ponto de vista da semiótica, de analisar a instância da expressão e de determinar as relações que se estabelecem entre expressão e conteúdo. Para tanto, abordamos especificamente os sistemas semióticos semi-simbólicos da poesia e da pintura que, ao contrário do que ocorre com as linguagens e os sistemas simbólicos, não podem prescindir, na tarefa de construção do sentido, da análise da expressão, nem do exame das correlações entre expressão e conteúdo. Para terminar, tentamos mostrar algumas decorrências da adoção de perspectiva semiótica no estudo da expressão, ressaltando a redefinição da questão da iconicidade em geral e nos textos visuais, em particular, e a caracterização de figuras da expres- 
são e de figuras do conteúdo, o que possibilita não só novas leituras do plástico e do poético, mas também o reconhecimento de procedimentos discursivos e textuais semelhantes no visual e no verbal.

São Paulo, setembro de 1984 


\section{NOTAS}

I Pensamos, sobretudo, na teoria e prática semióticas do visual, desenvolvidas no Groupe de Recherches Sémio-linguistiques por J.-M Floch e F Thürlemann, principalmente, que constituem o ponto de partida de nossas reflexões neste trabalho.

2 Veja-se, entre outros, Todorov, T; Estruturalismo e Poética. Tradução de J.P.Paes e F. Pessoa de Barros, 4 edição, São Paulo, Cultrix, 1976.

3 A ausência de reprodução dos quadros, por dificuldades de verba, prejudica bastante a leitura do texto. A pintura de Van Gogh está reproduzida na coleção Gênios da Pintura, da Abril Cultural.

4 Usamos algumas das conclusões do trabalho de pós-graduação de Rosângela Vieira Rocha, apresentado no curso de semiótica do visual que ministramos na Escola de Comunicações e Artes da Universidade de São Paulo, no primeiro semestre de 1978.

5 - Retomaremos certos resultados da análise semiótica da aquarela de Klee, efetuada por $F$ Thürlemann e publicada em Thürlemann, Felix; Paul Klee Analyse Sémiotique de Trois Peintures. Lausanne, Ed. L'Age d'Homme, 1982.

6 Rosa, João Guimarães; Tutaméia (Terceiras Estórias), 5* edição. Rio de Janeiro, José Olympio, 1979, p.38-40.

7 A fricção e a continuidade sonora aparecem sobretudo na reiteração do v/: "Jó Joaquim e Viléria retomaram-se, e conviveram, convolados, o verdadeiro e melhor de sua útil vida"' (p. 40).

8 Os reinos do amarelo

A terra lauta da mata produz e exibe/ um amarelo rico (senão o dos metais):/ o amarelo do maracujá e os da manga,/ o do oiti-da-praia, do caju e do cajá,/ amarelo vegetal, alegre de sol livre,/ beirando o estridente, de tão alegre,/ e que o sol eleva de vegetal a mineral,/ polindo-o, até um aceso metal de pele/ só que fere a vista uma marelo outro,/ e a fere embora baço (sol não o acende):/ amarelo aquém do vegetal, e se animal,/ de um animal cobre: pobre, podremente./ Só que fere a vista um amarelo outro:/ se animal, de homem: de corpo humano:/ de corpo e vida; de tudo o que segrega/ (sarro ou suor, bile intima ou ranho)/ ou sofre (o amarelo de sentir triste,/ de ser analfabeto, de existir aguado)/amarelo que no homem dali se adiciona/ o que há em ser pântano, ser-se fardo./ Embora comum ali, esse amarelo humano/ ainda dá na vista (mais pelo prodígio)/ pelo que tardam a secar, e ao sol dali/ tais pocas de amarelo, de escarro vivo. 
(Melo Neto, João Cabral de; Antologia Poética, 3a edição. Rio de Janeiro, José Olympio, 1978, p. 28)

9 - No primeiro verso do poema temos "Na terra lauta da mata"... e no último verso (da primeira estrofe) "de um animal cobre: pobre, podremente"

10 Ver Girassóis, de Van Gogh (nota 3)

11 - Ver Desenredo, de Guimarães Rosa (notas 6 e 7)

12 - Greimas, A.J.; Conditions D'une Sémiotique du Monde Natural. In Du Sens - Essais sémiotiques. Paris, Seuil, 1970, p.p. 49 - 91.

13 - Os fatos de sincretismo, que não serão abordados neste texto, devem ser tratados, a nosso ver, nessa mesma direção: caracterizam-se como relações entre materiais sensoriais diferentes (sonoro e visual, por exemplo) que manifestam uma mesma forma da expressão.

Veja-se a respeito floch, J.-M., Sémiotique Plastique et Langage Publicitaire. ACTES SÉMIOTIQUES DOCUMENTS, 1'1, 26. 1981.

14 - Se nas línguas naturais apenas o plano do conteúdo mantém relação intersemiótica com o mundo natural - excetuados os casos de sistemas semióticos semi-simbólicos -, nos objetos visuais, também o plano da expressão parece estar em correlação com o mundo sensível. Não se deve confundir tal dependência com cópia e sim entender "que as qualidades do mundo natural selecionadas servem para a construção do significante dos objetos planares" (Greimas, A.J.: semiótica figurativa e semiótica plástica. SIGNIFICAÇÃO - REVISTA BRASILEIRA DE SEMIÓTICA, No 4, JULHO DE 1984, p 27.) Ainda que se aceite que parte dos significantes construídos nas semióticas visuais resulta da apreensão de qualidades do mundo natural, esta constatação nada acrescenta ao impasse criado pela "representação" visual de elementos sonoros ou táteis, por exemplo. Tais procedimentos de "imitação" icônica precisam, portanto, ser considerados marginais nos sistemas semióticos visuais, da mesma forma que as onomatopéias no verbal. $\mathrm{O}$ reconhecimento de figuras do mundo resulta, antes de mais nada, de recursos figurativos discursivos que, como vimos, produzem a ilusão referencial. 